Keywords: osteosarcoma; hairy/enhancer-of-split related with YRPW motif protein 1 (HEY1); matrix metallopeptidase 9 (MMP9); metastasis; NOTCH

\title{
Hairy/enhancer-of-split related with YRPW motif protein 1 promotes osteosarcoma metastasis via matrix metallopeptidase 9 expression
}

\author{
A Tsuru ${ }^{1,4}$, T Setoguchi ${ }^{*}, 2,4, Y$ Matsunoshita ${ }^{1}$, H Nagao-Kitamoto ${ }^{1}$, S Nagano ${ }^{1}$, M Yokouchi ${ }^{1}$, S Maeda $^{3}$, \\ Y Ishidou ${ }^{3}$, T Yamamoto $^{1}$ and S Komiya ${ }^{1}$ \\ ${ }^{1}$ Department of Orthopaedic Surgery, Graduate School of Medical and Dental Sciences, Kagoshima University, 8-35-1 \\ Sakuragaoka, Kagoshima 890-8520, Japan; ${ }^{2}$ The Near-Future Locomotor Organ Medicine Creation Course (Kusunoki Kai), \\ Graduate School of Medical and Dental Sciences, Kagoshima University, 8-35-1 Sakuragaoka, Kagoshima 890-8520, Japan and \\ ${ }^{3}$ Department of Medical Joint Materials, Graduate School of Medical and Dental Sciences, Kagoshima University, 8-35-1 \\ Sakuragaoka, Kagoshima 890-8520, Japan
}

Background: Activation of the Notch pathway has been reported in various types of cancers. However, the role of the hairy/ enhancer-of-split related with YRPW motif protein 1 (HEY1) in osteosarcoma is unknown. We examined the function of HEY1 in osteosarcoma.

Methods: Expression of HEY1 was studied in human osteosarcoma. The effects of HEY1 in osteosarcoma were evaluated in vitro and in a xenograft model. Moreover, we examined the function of matrix metallopeptidase 9 (MMP9) as a downstream effector of HEY1.

Results: HEY1 was upregulated in human osteosarcoma. Knockdown of HEY1 inhibited the invasion of osteosarcoma cell lines. In contrast, the forced expression of HEY1 increased the invasion of mesenchymal stem cell. In addition, lung metastases were significantly inhibited by the knockdown of HEY1. We found that MMP9 was a downstream effector of HEY1 that promotes the invasion of osteosarcoma cells. Knockdown of HEY1 decreased the expression of MMP9. Addition of MMP9 rescued the invasion of osteosarcoma cells that had been rendered less invasive by knockdown of HEY1 expression.

Conclusions: Our findings suggested that HEY1 augmented the metastasis of osteosarcoma via upregulation of MMP9 expression. Therefore, inhibition of HEY1 may be a novel therapeutic strategy for preventing osteosarcoma metastasis.

Osteosarcoma is the most common malignant bone sarcoma in children and adolescents. Neoadjuvant therapy has improved long-term survival for up to $80 \%$ of patients with localised disease (Hegyi et al, 2011). Twenty percent of patients have detectable metastases at the time of diagnosis (Link et al, 1986; Marina et al, 2004). Osteosarcoma patients with metastasis or recurrence still have a poor prognosis (Marina et al, 2004). It is important, therefore, to understand the heterogeneity and complexity of the molecular regulation of osteosarcoma metastasis.

Notch signalling is activated when Notch ligands interact with Notch receptors promoting proteolytic cleavage that results in the

\footnotetext{
*Correspondence: Dr T Setoguchi; E-mail: setoro@m2.kufm.kagoshima-u.ac.jp
}

${ }^{4}$ These authors contributed equally to this work. 
release of the Notch intracellular domain and subsequent translocation to the nucleus (Kopan and Ilagan, 2009). The Notch intracellular domain forms a transcriptional activation complex with RBPJ transcription factors (CBF1/RBP-Jk, Su(H), Lag-1) and converts them from repressors to activators, promoting transcription of the target genes involved in various developmental and differentiation processes (Koch et al, 2013). Aberrant activation of Notch signalling also has a role in various types of malignant tumour pathogenesis (Shao et al, 2012). We previously reported that Notch signalling was activated in human osteosarcoma and inhibition of Notch signalling prevented osteosarcoma growth in vitro and in vivo (Tanaka et al, 2009). In this report, we examined the role of hairy/enhancer-of-split related with YRPW motif protein 1 (HEY1), a transcription factor regulated by the Notch pathway, in human osteosarcoma. We found that expression of HEY1 is upregulated in human osteosarcoma. In addition, HEY1 promoted osteosarcoma cell invasion and lung metastasis via upregulation of MMP9.

\section{MATERIALS AND METHODS}

Cell lines and reagents. Osteosarcoma cell lines 143B, HOS, Saos2, U2OS and MG-63 were received from the American Type
Culture Collection (ATCC, Manassas, VA, USA). NOS-1 and HSOs-1 cell lines were obtained from the Riken Bioresource Center (Tsukuba, Japan). Cell lines were cultured in Dulbecco's modified Eagle's medium (DMEM) supplemented with $10 \%$ foetal bovine serum (FBS), $100 \mathrm{U} \mathrm{ml}^{-1}$ penicillin, and $100 \mu \mathrm{g} \mathrm{ml}^{-1}$ streptomycin. $\mathrm{Hu}-09, \mathrm{HuO}-3 \mathrm{~N} 1$ and NY cell lines were obtained from the Health Science Research Resources Bank (HSRRB; Osaka, Japan). Cell lines were cultured in Roswell Park Memorial Institute 1640 medium supplemented with 10\% FBS. Normal human osteoblast cells (NHOst; Sanko Junyaku, Tokyo, Japan) were grown in OBMTM medium (Cambrex, East Rutherford, NJ, USA). A human bone marrow-derived mesenchymal stem cell (MSC) line, UBE6T15, was purchased from HSRRB. UBE6T15 cells were grown in DMEM with 10\% FBS.

Real-time PCR. For real-time polymerase chain reaction (PCR), total RNA from osteosarcoma cell lines and HEY1 siRNAtransfected osteosarcoma cells were isolated by using TRIzol (Invitrogen, Carlsbad, CA, USA) and purified by using the mirVana miRNA isolation kit (Invitrogen). Reactions were run using SYBR Green (BIO-RAD, Hercules, CA, USA). The comparative $\mathrm{Ct}(\Delta \Delta \mathrm{Ct})$ method was performed to determine the fold-change of mRNA expression using actin-beta $(A C T B)$ as a reference. Each sample was run in triplicate. The primer sequences used were as follows: HEY1: 5'-CGAGGTGGAGAAGGAGAGTG-3',

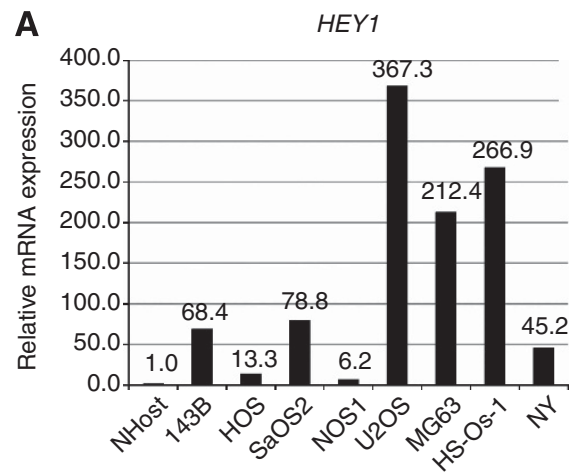

HEY2



B



Tubulin
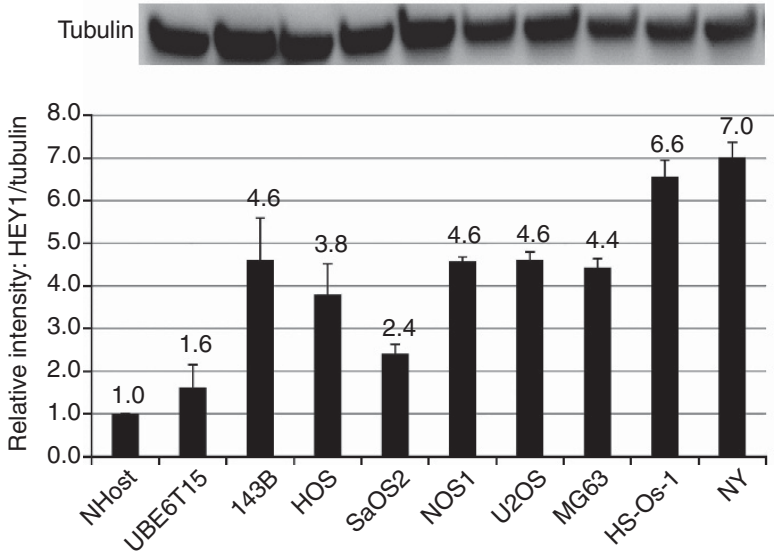

Figure 1. Increased expression of HEY1 and HEY2 in human osteosarcoma cell lines. (A) Total RNA collected from osteosarcoma cell lines was examined by using real-time PCR. A comparative $\mathrm{Ct}(\Delta \Delta \mathrm{C} t)$ analysis was performed to examine fold changes in mRNA expression compared with $\beta$-actin. Real-time PCR showed that eight out of eight human osteosarcoma cell lines had an increased expression of HEY1 compared with normal osteoblasts (NHOst). Five out of eight human osteosarcoma cell lines also showed increased expression of HEY2. The experiment was performed in triplicate with similar results. (B) Protein expression of HEY1 were examined by western blot. All osteosarcoma cell lines increased the expression of HEY1 protein. The experiment was performed in triplicate with similar results. 
5' -CTG GGTACCAGCCTTCTCAG-3'; MMP9: 5' -TTGACAGCGA CAAGAAGTGG-3' ${ }^{\prime}$ 5'-GCCATTCACGTCGTCCTTAT-3'; ACTB: $5^{\prime}$-AGAAAATCTGGCACCACACC- $3^{\prime}$ and $5^{\prime}$-AGAGGCGTACA GGGATAGCA-3'.

HEY1 small interfering RNA transfection. Control siRNA (S20C-0600) was obtained from B-Bridge International, Inc. (Tokyo, Japan). HEY1 siRNA (sc-37913) was purchased from Santa Cruz Biotechnology, Inc. (Santa Cruz, CA, USA). HEY1 siRNA (LQ-008709-00-0002) was purchased from Thermo Fisher Scientific, Inc. (Yokohama, Japan). All siRNA transfection experiments were performed by using Lipofectamine RNAiMAX (Life Technologies, Carlsbad, CA, USA) transfection reagents according to the manufacturer's protocol.

Expression vector. The pCMV6-Entry vector (PS100001) and HEY1 expression vector (RC200257) were purchased from OriGene Technologies (Rockville, MD, USA). All plasmids were transfected into UBE6T15 cells by using electroporation (Amaxa Nucleofector; Lonza, Tokyo, Japan).

A

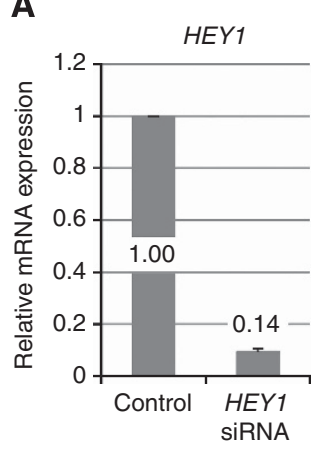

Control

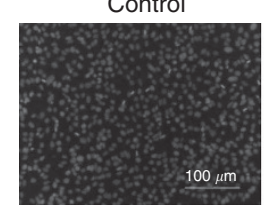

C

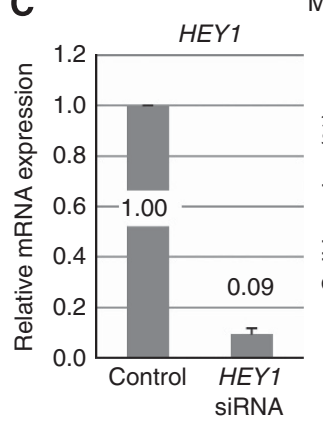

Control

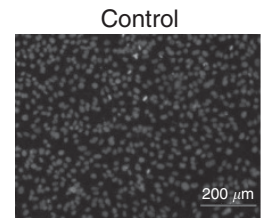

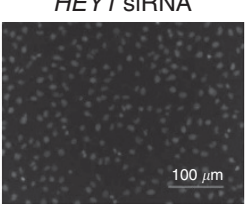

143B

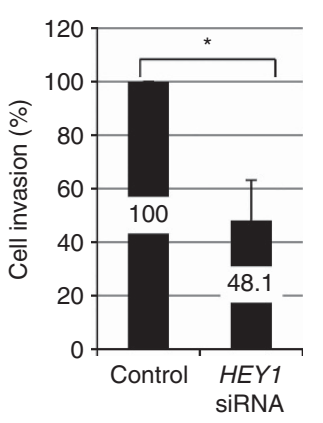

${ }^{*} P<0.05$

MG63
Cell proliferation assay. We seeded $5 \times 10^{2}$ cells per $100 \mu$ in a 96-well plate. Cell growth was measured daily using the WST-1 cell proliferation assay (Roche, Basel, Switzerland).

Invasion assay. Invasive activity was measured using $\mathrm{BD}$ Matrigel (BD Bioscience, Franklin Lakes, NJ, USA) according to the manufacturer's protocol. Briefly, transfected osteosarcoma cells in $2 \mathrm{ml}$ of serumfree medium were seeded into the upper chamber of the system. The bottom wells in the system were filled with DMEM and 10\% FBS. After incubation (16-24h), the cells in the upper chamber were removed, and the cells on the bottom membrane were stained. The cells that invaded were counted in five random fields of the membrane. The invasion efficiency of the control cells was estimated as $100 \%$. To confirm whether HEY1 induce a cell invasion, we performed an invasion assay which equalises the number of each osteosarcoma cell line. To determine whether MMP9 rescued the decrease in the invasive activity, we added the recombinant active human MMP9 (Sino Biological Inc., Peking, China) to the upper chamber.

Western blot. Cells were lysed by using NP40 lysis buffer $(0.5 \%$ NP40, $10 \mathrm{~mm}$ Tris- $\mathrm{HCl}$ (pH 7.4), $150 \mathrm{~mm} \mathrm{NaCl}, 3 \mathrm{~mm}$ pAPMSF

\section{B}



HS-Os-1
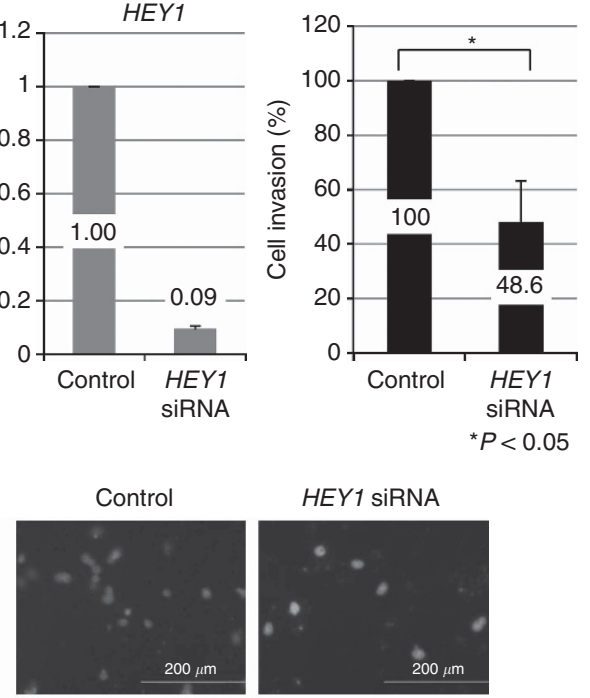

HEY1 siRNA

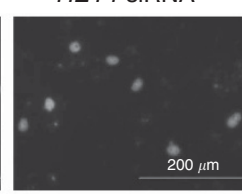

Figure 2. HEY1 promotes invasion of osteosarcoma cells. HEY1 siRNA-treated osteosarcoma cell lines or control siRNA-treated osteosarcoma cells were examined by using an invasion assay. Treatment with HEY1 siRNA decreased the expression of HEY1 mRNA. Column graphs show percent of invading cells after the invasion assay. Percent of invading cells in control siRNA-transfected cell lines were defined relative to an invasion of $100 \%$. Representative photomicrographs show invaded cells (lower). Scale bar is $200 \mu \mathrm{m}$. ${ }^{\star} P<0.05$, Student's $t$-test. 
(Wako Chemicals, Kanagawa, Japan), $5 \mathrm{mg} \mathrm{ml}^{-1}$ aprotinin (Sigma, St. Louis, MO, USA), 2 mm sodium orthovanadate (Wako Chemicals) and $5 \mathrm{~mm}$ EDTA. Lysates were subjected to SDS-PAGE followed by immunoblotting. The following antibodies were used: anti-HEY1 $(1: 200$, ab22614, Abcam, Cambridge, UK; Figure 1B, Supplementary Figure 2B), anti HEY1 (1:200, H00023462-M01, Abnova, Taipei, Taiwan; Figure 3$)$ and $\beta$-tubulin $(1: 1000, \mathrm{DM} 1 \mathrm{~A}$, Sigma-Aldrich Co. LLC). Detection was performed by using the enhanced chemiluminescence detection system (Amersham, Giles, UK).

Gene infection for in vivo examination. Cells were infected with control shRNA lentiviral particles (sc-108080), HEY1 shRNA lentiviral particles (sc-37914-V) or copGFP control lentiviral particles (sc-108084). All lentiviral particles were purchased from Santa Cruz Biotechnology. Infected cells were selected in $1 \mathrm{mg} \mathrm{ml}^{-1}$ neomycin or $1-2 \mathrm{~g} \mathrm{ml}^{-1}$ puromycin.

Animal studies of osteosarcoma lung metastasis. For metastasis experiments, $143 \mathrm{~B}$ cells $\left(5 \times 10^{5}\right)$ were transfected with GFP lentiviral particles (Santa Cruz), as previously reported (Matsunoshita et al, 2011; Nagao-Kitamoto et al, 2014). Briefly, control or HEY1 shRNA-transfected 143B cells (control shRNA/ 143B and HEY1 shRNA/143B, respectively) were infected with GFP lentiviral particles. Stably GFP-expressing 143B cells $\left(1 \times 10^{6}\right)$ were suspended in $100 \mu \mathrm{l}$ of Matrigel (BD Biosciences). Cell suspensions were inoculated into the left-knee joint of 5-week-old nude mice (Japan SLC, Inc., Hamamatsu, Japan). Mice were sacrificed 7.5 weeks. Lung metastases were evaluated by using fluorescence microscopy (Leica Microsystems AG, Heerbrugg, Switzerland). All animal experiments were performed in compliance with the guidelines of and were accepted by the Animal Science Laboratory, Frontier Science Research Center, Kagoshima University. All efforts were made to minimise animal suffering, to reduce the number of animals used and to utilise possible alternatives to in vivo techniques.

ELISA assay. Expression levels of MMP9 protein were assayed using specific enzyme-linked immunosorbent assay kits according to the manufacturer's instructions (Abcam).

Patient specimens. All human osteosarcoma biopsy specimens were obtained from primary lesions. Biopsies were performed before chemotherapy and used for diagnostic purposes. Normal bone tissue was obtained from the femur during total hip arthroplasty. The Institutional Review Board of Kagoshima University accepted the study protocol. All patients and control subjects gave written informed consent to participate in the study.

Statistical analysis. Statistical analyses were performed using the Student's $t$-test with Microsoft Office Excel (Microsoft, Albuquerque, NM, USA). The Mann-Whitney U test was conducted by Souken Co., Inc. (Tokyo, Japan). Spearman's rank correlation coefficient was performed with Excel Statistics 2012 (SSRI, Tokyo, Japan). $P$-values $<0.05$ were considered statistically significant.

\section{RESULTS}

HEY1 and HEY2 are upregulated in human osteosarcoma cell lines. We previously reported that Notch-related genes were
A



B

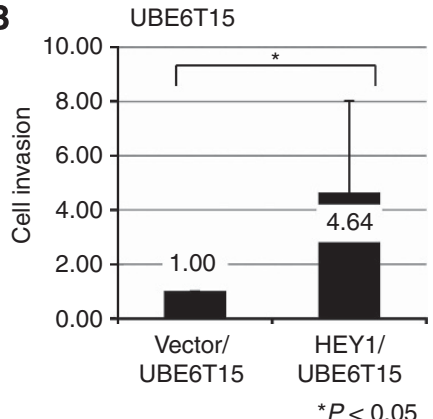

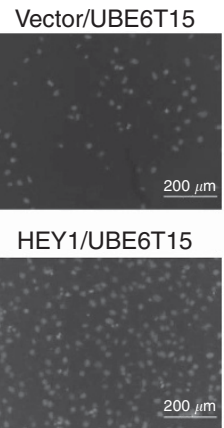

Expression of HEY1

C

Cell invasion

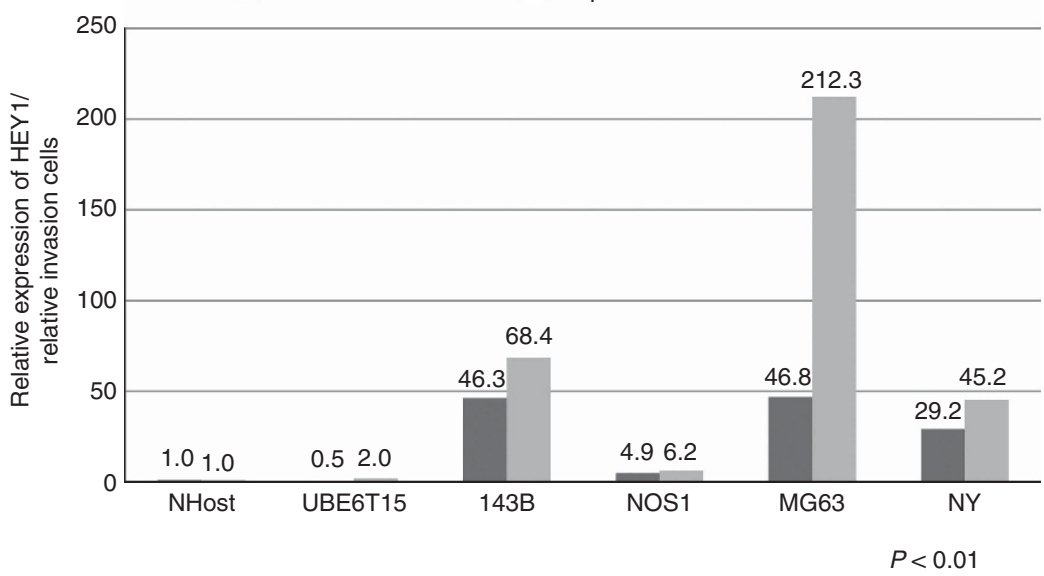

Figure 3. Forced expression of HEY1 promotes invasion of Mesenchymal stem cell. HEY1 expression vector-transfected mesenchymal stem cell or control vector-transfected mesenchymal stem cell were examined by using an invasion assay. (A) Expression of HEY1 was determined using western blotting. (B) Column graphs show percent of invading cells after the invasion assay. Percent of invading cells in control vectortransfected cell were defined relative to an invasion of $100 \%$. Representative photomicrographs show invaded cells. Scale bar is $200 \mu$ m. ${ }^{*}<0.05$, Student's t-test. (C) Real-time PCR and invasion assays were performed to examine the relationship between $H E Y 1$ expression and invasion. $P<0.01$, Pearson correlation coefficient. 
upregulated in human osteosarcoma specimens (Tanaka et al, 2009). We focused on HEY1 and HEY2 because their function in human osteosarcoma is not well understood. Real-time PCR showed that many human osteosarcoma cell lines elevated HEY1 and HEY2 (Figure 1A), and that 8 out of 10 human osteosarcoma biopsy specimens had showed an increased HEY1 and HEY2 expression compared with normal bone (Tanaka et al, 2009). Western blot analysis revealed that HEY1 protein levels were elevated in osteosarcoma cell lines compared with NHost (normal osteoblast) (Figure 1B).

Knockdown of HEY1 prevents osteosarcoma invasion but not proliferation. To examine the function of HEY1 and HEY2 in human osteosarcoma, we examined cell proliferation by using the WST-1 assay. Knockdown of HEY1 by siRNA (sc-37913: Santa Cruz Biotechnology) decreased the expression of HEY1 mRNA and protein (Figure 2 and Supplementary Figure 1A, B). Knockdown of HEY1 or HEY2 did not affect the proliferation of human osteosarcoma cells (Supplementary Figure 1B). The cell invasion assay showed that the knockdown of HEY1 prevented $143 \mathrm{~B}$ osteosarcoma cell invasion (Figure 2A). To rule out the possibility of off-target effects, we examined an alternative HEY1-specific siRNA (LQ-008709-00-0002: Thermo Fisher Scientific) which also inhibited invasion (Supplementary Figure 2A). In addition, knockdown of HEY1 prevented HS-Os-1 and MG63 osteosarcoma cell invasion (Figure 2B and C). Knockdown of HEY2, however, did not affect the invasion of osteosarcoma cells (data not shown).

HEY1 promotes invasion of osteosarcoma and MSCs. We examined the effect of forced expression of HEY1 on invasion. Because osteosarcoma is thought to originate from MSCs (27), we used UBE6T15, a human MSC line, to examine the role of HEY1 in invasion. UBE6T15 cells transfected with the HEY1 expression vector showed upregulated HEY1 protein levels (Figure 3A). Invasion of HEY1-transfected UBE6T15 cells was greater than that of control vector-transfected cells (Figure 3B). We examined the correlation between expression of HEY1 and invasion of osteosarcoma cell lines. RT-PCR and invasion assays showed that osteosarcoma cells with high expression of HEY exhibited increased invasive activity (Figure $3 \mathrm{C}$ ).

Knockdown of HEY1 prevents lung metastasis of osteosarcoma cells. We evaluated the role of HEY1 in lung metastasis in a mouse xenograft model. Knockdown of HEY1 did not affect the growth of original site osteosarcoma in knee joints (data not shown). The percentage and number of lung metastases in mice inoculated with HEY1 shRNA/143B-GFP was significantly less than in control mice inoculated with shRNA/143B-GFP (Figures $4 \mathrm{~A}$ and B). In addition, the area of lung metastasis in mice inoculated with $H E Y 1$ shRNA/143B-GFP was significantly smaller than in control mice inoculated with shRNA/143B-GFP (Figure 4C). These findings suggest that knockdown of HEY1 inhibits osteosarcoma lung metastasis.

MMP9 acts downstream of HEY1 to regulate invasion of osteosarcoma. To gain further insight underlying HEY1-mediated invasion of osteosarcoma, we selected genes that were reported to regulate invasion of cancer cells. RT-PCR revealed that MMP9 was decreased using knockdown of HEY1 in osteosarcoma cells (Figure 5 and Supplementary Figure 3A). The ELISA assay showed that knockdown of HEY1 decreased the expression of MMP9 protein (Figure 6A). The number of invasive cells was decreased in HEY1 shRNA cells; however, this phenotype was largely reversed by the addition of active MMP9 protein (Figure 6B). These findings suggest that HEY1 promotes osteosarcoma cell invasion via expression of MMP9.

Strong correlation between HEY1 and MMP9 expression. To validate whether HEY1 expression was correlated with MMP9 expression, we measured the expression of MMP9 protein in osteosarcoma cell line by ELISA assay. We found that the expression of HEY1 correlated with MMP9 protein (Figure 7). At last, we examined the expression of MMP9 in osteosarcoma patient specimens. RT-PCR revealed that MMP9 was overexpressed in osteosarcoma specimens (Supplementary Figure 3B).

\section{DISCUSSION}

Although dysregulated Notch pathway is an attractive target to treat cancers, it is possible that the inhibition of Notch pathway by $\gamma$-secretase inhibitors, Notch antisense and or anti-Notch monoclonal antibodies could result in toxicity of normal stem cells, gastrointestinal toxicity, diarrhoea, hepatotoxicity and nephrotoxicity (Searfoss et al, 2003; van Es et al, 2005; Garber, 2007; Wu et al, 2010; Purow, 2012). Given the potential toxicity, specifically targeting a Notch target gene instead might provide greater clinical benefit. We showed that knockdown of HEY1 prevented osteosarcoma invasion and lung metastasis. These findings suggest that targeting HEY1 may be a better way to prevent osteosarcoma
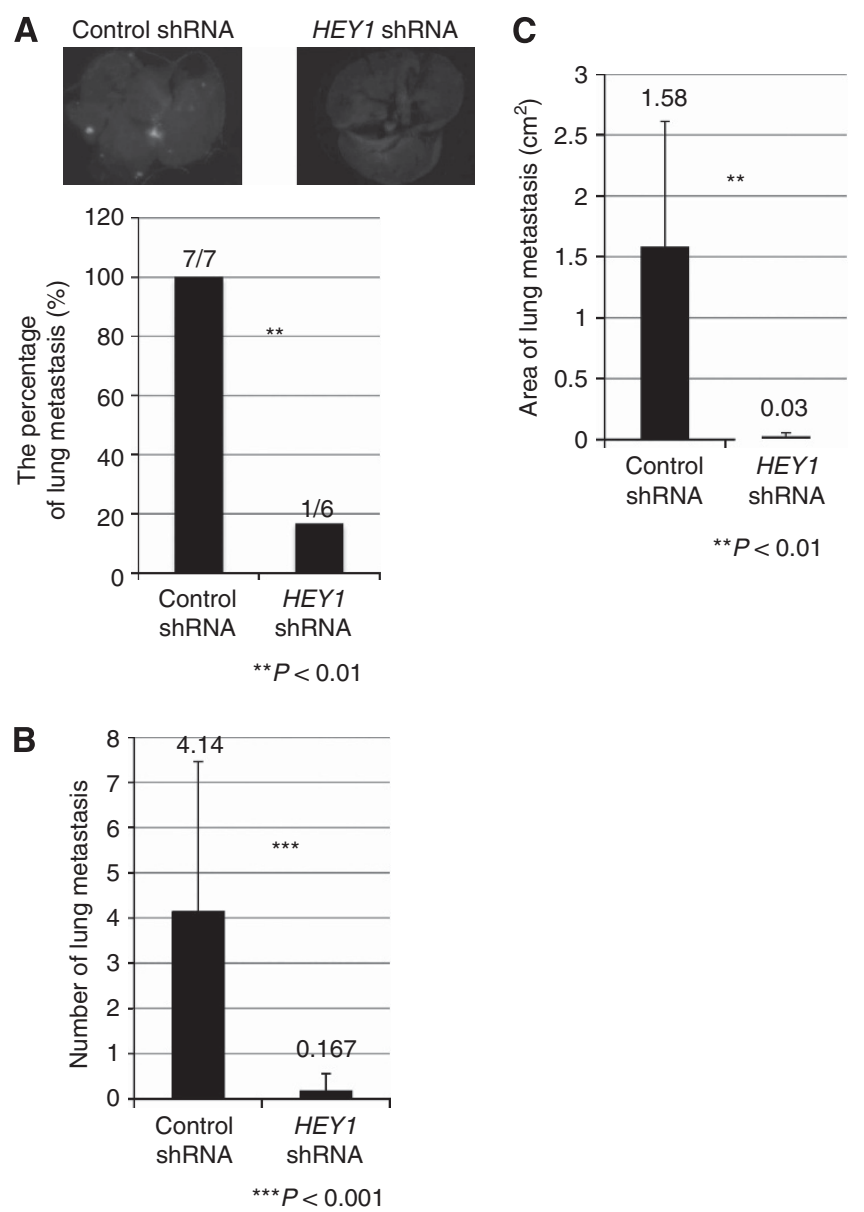

Figure 4. Knockdown of HEY1 prevents osteosarcoma cells from metastasising to the lung. Stably GFP-expressing control shRNA/143B or HEY1 shRNA/143B cells were inoculated into the left knee joint of nude mice ( $n=7$ for control, $n=6$ for HEY1 shRNA group). Seven and a half weeks post inoculation, the mice were sacrificed. Lung metastases were evaluated by using fluorescence microscopy, and the number of metastatic tumours was calculated by using Image $\mathrm{J}$ software. Photographs show lung metastases for each group. Knockdown of HEY1 decreased the percentage of mice with lung metastases (A), the number of lung metastases (B), and the area of lung metastases (C). ${ }^{\star} P<0.05,{ }^{\star \star} P<0.01$, Mann-Whitney $U$ test and Student's $t$-test. 

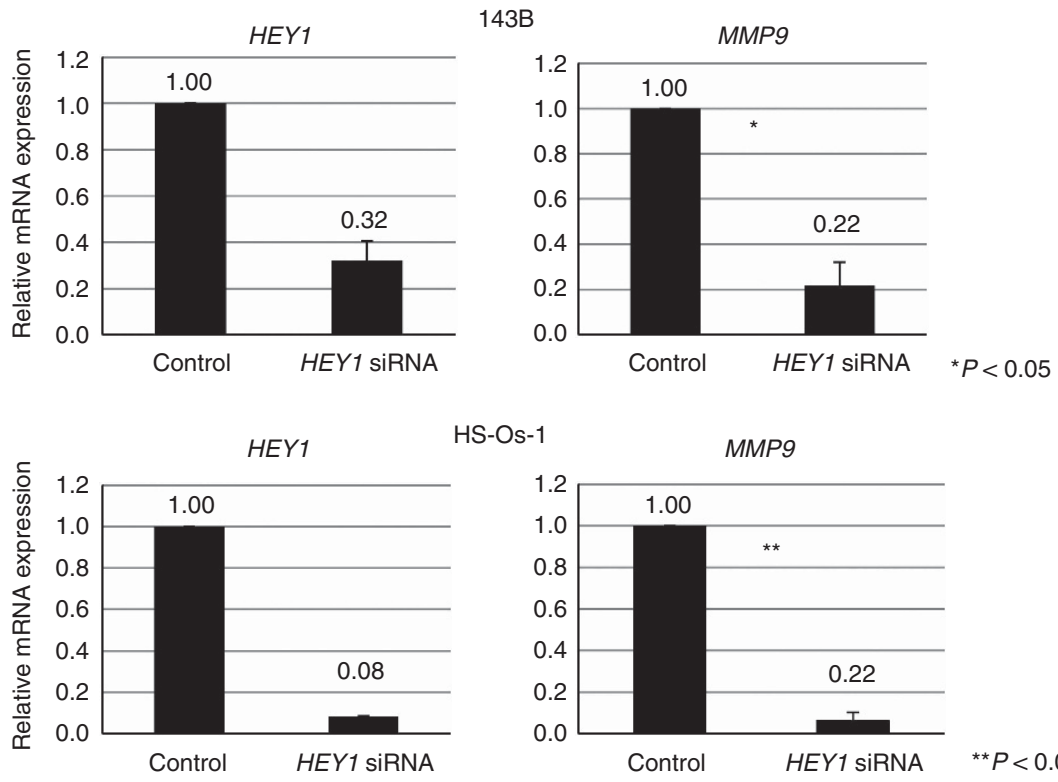

HS-Os-1
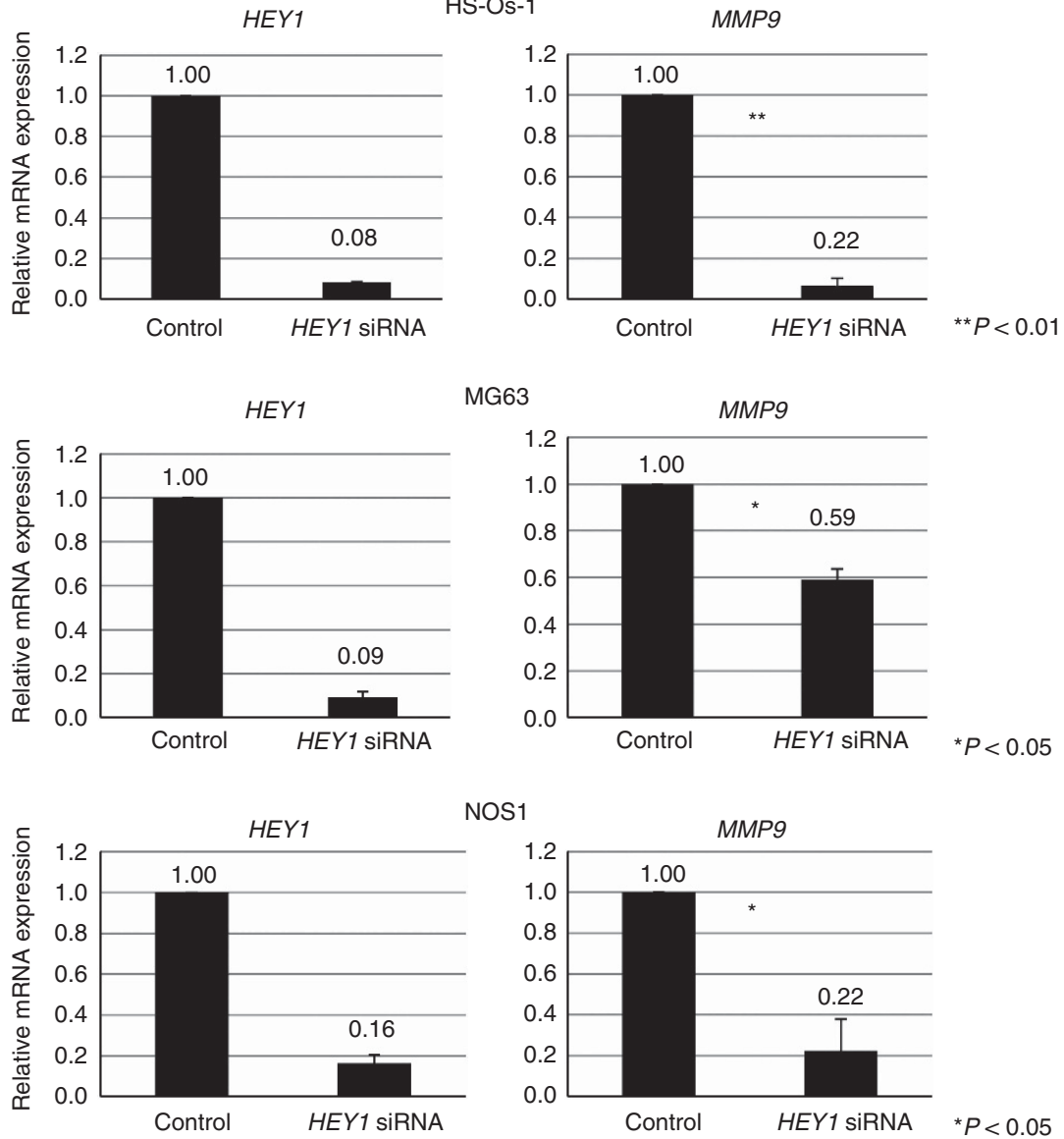

Figure 5. Knockdown of HEY1 decreased the expression of MMP9 in human osteosarcoma cells. MMP9 expression levels in 143B, HS-Os-1, MG63 and NOS1 cells were assessed by using real-time PCR $24 \mathrm{~h}$ after transfection with control siRNA or HEY1 siRNA. The experiment was performed in triplicate with similar results. ${ }^{\star} P<0.05,{ }^{\star \star} P<0.01$, Student's $t$-test.

metastasis and provide greater clinical benefit than Notch inhibitors.

Expression of HEY1 is regulated by Notch signalling (Maier and Gessler, 2000; Nakagawa et al, 2000). In addition, bone morphogenetic proteins (BMPs) and transforming growth factor beta (TGF- $\beta$ ) increase the expression of HEY1 (de Jong et al, 2004; Zavadil et al, 2004). It has been reported that BMPs and TGF- $\beta$ regulate osteosarcoma cell motility and lung metastasis (Sotobori et al, 2006; Weiss et al, 2006; Zhang et al, 2013). Our findings suggest that inhibition of HEY1 may prevent osteosarcoma invasion and lung metastasis caused by not only the Notch pathway but also by BMPs and TGF- $\beta$ activation.

Although HEY1 is involved in the development of the heart, neurogenesis and osteogenesis (Sakamoto et al, 2003; Kokubo et al, 2005, 2007; Sharff et al, 2009; Salie et al, 2010), it has been reported that HEY1 over-expression was a negative prognostic factor for several cancers (Hulleman et al, 2009; Mann et al, 2012; Candy et al, 2013). Our findings also suggest that over-expression of HEY1 may increase lung metastasis, which worsens the prognosis. Further studies using clinical samples are needed to examine the association of HEY1 expression with prognosis.

MMPs are involved in the degradation of the extracellular matrix. MMP2 and MMP9 are the most consistently overexpressed in malignant tumours and are associated with aggressiveness, metastatic potential and poor prognosis (Hidalgo and Eckhardt, 2001). HEY1 expression is regulated by many signalling molecules including CD147, the PI3K/AKT pathway, epidermal growth factor receptor and fibroblast growth factor 11 (Toole, 2003; Hu et al, 2014; Wang et al, 2014; Zhang et al, 2014). We showed that MMP9 was upregulated in human osteosarcoma specimens and cell lines as previously reported (Kawashima et al, 1994; Cho et al, 2007; Xin et al, 2009). Knockdown of HEY1 decreased the expression of MMP9. In addition, reduction of osteosarcoma cell invasion by HEY1 knockdown was nullified by the addition of active MMP9 protein. It has been reported that activation of Notch signalling promotes MMP9-mediated cell 
A

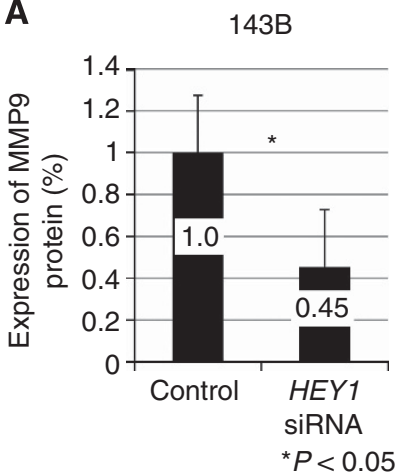

HS-Os-1

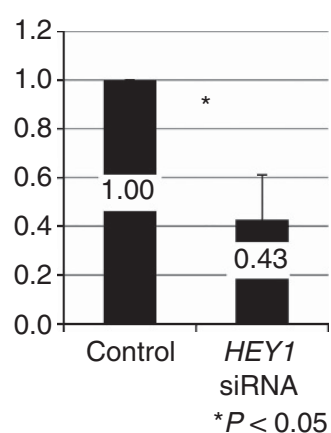

HOS



B

Cell invasion assay

$143 B$

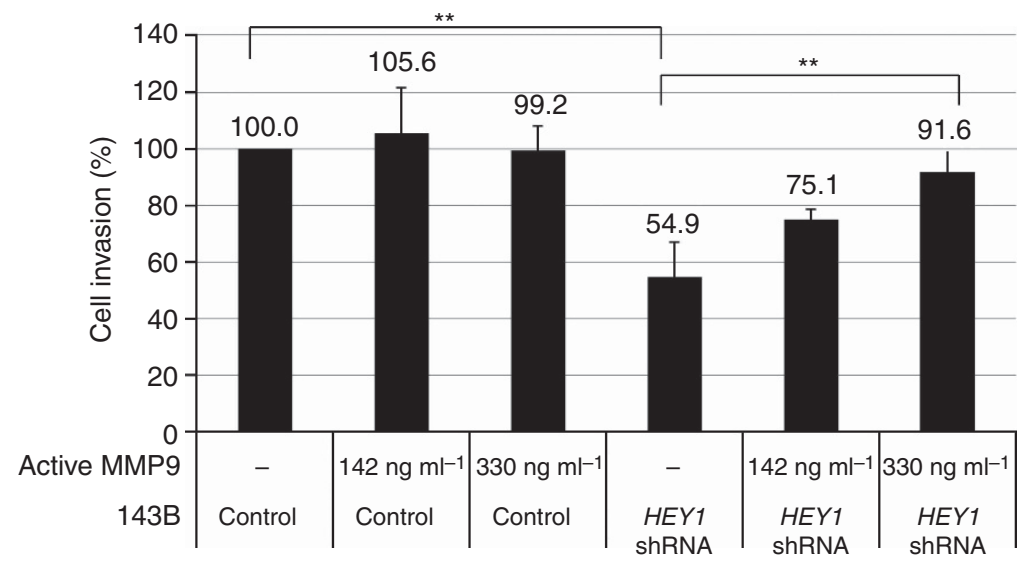

${ }^{* *} P<0.01$

Figure 6. HEY1-regulated osteosarcoma invasion is mediated by MMP9. (A) ELISA assay was performed to examine the expression of MMP9 following control siRNA or HEY1 siRNA transfection. (B) Control siRNA/143B or HEY1 siRNA/143B transfected cells were examined by using the invasion assay. The number of invasive cells was decreased in HEY1 shRNA-expressing cells. To determine if a decrease of invasion due to HEY1 knockdown could be reversed by the addition of active MMP9 protein or not, the invasion assay was performed with and without active MMP9. The experiment was performed in triplicate with similar results. ${ }^{\star} P<0.05,{ }^{\star \star} P<0.01$, Student's $t$-test.

- HEY1 = MMP9

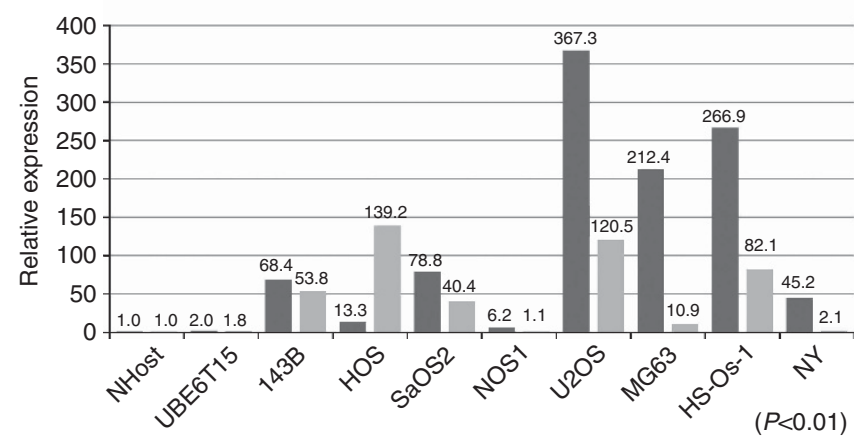

Figure 7. Strong association between HEY1 and MMP9 expression. We examined the expression of HEY1 and MMP9. HEY1 and MMP9 mRNA expression was examined by using NHost (normal osteoblast), UBE6T15 (mesenchymal stem cell), and eight human osteosarcoma cell lines. Spearman's rank correlation coefficient test showed that correlation between HEY1 and MMP9 expression was significant. The experiment was performed in triplicate with similar results. $P<0.01$.

invasion of human cancers (Wang et al, 2006; Bin Hafeez et al, 2009; Gao et al, 2012). Cancers and neural stem cells that express HEY1 acquire high invasive potential (Bolos et al, 2013; Sailer et al, 2013). Our findings suggest that Notch-regulated cell invasion and MMP9 expression mediated by HEY1 occurs not only in osteosarcoma but also in other cancers as well as endothelial cells in rheumatoid arthritis.

Although we showed that HEY1 regulates the expression of MMP9, we have not yet defined whether MMP9 is a direct transcriptional target of HEY1. Villaronga et al (2010) reported that HEY1-L94M, with a single nucleotide polymorphism, behaves as a potent transcriptional co-activator of the androgen receptor. Heisig et al (2012) reported that HEY proteins primarily act as direct transcriptional repressors, whereas their role in gene activation appears to be because of secondary or indirect effects. Consistent with these findings, results from our chip assay revealed that HEY1 did not bind to the MMP9 promoter (data not shown). Additional studies will be necessary to determine which factor or HEY1 gene variant mediates the expression of MMP9 related to HEY1 expression.

In conclusion, we found new clues associating HEY1 with osteosarcoma metastasis, which opens up the possibility of targeted inhibition of HEY1 for the treatment of osteosarcoma metastasis.

\section{ACKNOWLEDGEMENTS}

We are grateful to Hui Gao for excellent technical assistance. We thank the joint research laboratory of Kagoshima University Graduate School of Medical and Dental Sciences. This work was supported by Grants-in-Aid for Scientific Research (KAKENHI) 
(C) 19591725, (C) 20591786, (C) 21591919, (C) 21591920, (C) 22591663 and (C) 23592195, a Grant-in-Aid from the Ministry of Health, Labour and Welfare of Japan for the Third Term Comprehensive Control Research for Cancer and Scientific Research on Priority Areas 201201976 to H. Nagao from the Grants-in-Aid for JSPS Fellows.

\section{CONFLICT OF INTEREST}

The authors declare no conflict of interest.

\section{REFERENCES}

Bin Hafeez B, Adhami VM, Asim M, Siddiqui IA, Bhat KM, Zhong W, Saleem M, Din M, Setaluri V, Mukhtar H (2009) Targeted knockdown of Notch1 inhibits invasion of human prostate cancer cells concomitant with inhibition of matrix metalloproteinase-9 and urokinase plasminogen activator. Clin Cancer Res 15(2): 452-459.

Bolos V, Mira E, Martinez-Poveda B, Luxan G, Canamero M, Martinez AC, Manes S, de la Pompa JL (2013) Notch activation stimulates migration of breast cancer cells and promotes tumor growth. Breast Cancer Res 15(4): R54.

Candy PA, Phillips MR, Redfern AD, Colley SM, Davidson JA, Stuart LM, Wood BA, Zeps N, Leedman PJ (2013) Notch-induced transcription factors are predictive of survival and 5-fluorouracil response in colorectal cancer patients. Br J Cancer 109(4): 1023-1030.

Cho HJ, Lee TS, Park JB, Park KK, Choe JY, Sin DI, Park YY, Moon YS, Lee KG, Yeo JH, Han SM, Cho YS, Choi MR, Park NG, Lee YS, Chang YC (2007) Disulfiram suppresses invasive ability of osteosarcoma cells via the inhibition of MMP-2 and MMP-9 expression. J Biochem Mol Biol 40(6): 1069-1076.

de Jong DS, Steegenga WT, Hendriks JM, van Zoelen EJ, Olijve W, Dechering KJ (2004) Regulation of Notch signaling genes during BMP2-induced differentiation of osteoblast precursor cells. Biochem Biophys Res Commun 320(1): 100-107.

Gao W, Sweeney C, Connolly M, Kennedy A, Ng CT, McCormick J, Veale DJ, Fearon U (2012) Notch-1 mediates hypoxia-induced angiogenesis in rheumatoid arthritis. Arthritis Rheum 64(7): 2104-2113.

Garber K (2007) Notch emerges as new cancer drug target. J Natl Cancer Inst 99(17): 1284-1285.

Hegyi M, Semsei AF, Jakab Z, Antal I, Kiss J, Szendroi M, Csoka M, Kovacs G (2011) Good prognosis of localized osteosarcoma in young patients treated with limb-salvage surgery and chemotherapy. Pediatr Blood Cancer 57(3): $415-422$.

Heisig J, Weber D, Englberger E, Winkler A, Kneitz S, Sung WK, Wolf E, Eilers M, Wei CL, Gessler M (2012) Target gene analysis by microarrays and chromatin immunoprecipitation identifies HEY proteins as highly redundant bHLH repressors. PLoS Genet 8(5): e1002728.

Hidalgo M, Eckhardt SG (2001) Development of matrix metalloproteinase inhibitors in cancer therapy. J Natl Cancer Inst 93(3): 178-193.

Hu S, Li L, Yeh S, Cui Y, Li X, Chang HC, Jin J, Chang C (2014) Infiltrating T cells promote prostate cancer metastasis via modulation of FGF11$>$ miRNA-541-> androgen receptor (AR)- > MMP9 signaling. Mol Oncol 9(1): 44-57.

Hulleman E, Quarto M, Vernell R, Masserdotti G, Colli E, Kros JM, Levi D, Gaetani P, Tunici P, Finocchiaro G, Baena RR, Capra M, Helin K (2009) A role for the transcription factor HEY1 in glioblastoma. J Cell Mol Med 13(1): 136-146.

Kawashima A, Nakanishi I, Tsuchiya H, Roessner A, Obata K, Okada Y (1994) Expression of matrix metalloproteinase 9 (92-kDa gelatinase/type IV collagenase) induced by tumour necrosis factor alpha correlates with metastatic ability in a human osteosarcoma cell line. Virchows Arch 424(5): 547-552.

Koch U, Lehal R, Radtke F (2013) Stem cells living with a Notch. Development (Cambridge, England) 140(4): 689-704.

Kokubo H, Miyagawa-Tomita S, Nakazawa M, Saga Y, Johnson RL (2005) Mouse hesr 1 and hesr2 genes are redundantly required to mediate Notch signaling in the developing cardiovascular system. Dev Biol 278(2): 301-309.
Kokubo H, Tomita-Miyagawa S, Hamada Y, Saga Y (2007) Hesr1 and Hesr2 regulate atrioventricular boundary formation in the developing heart through the repression of Tbx2. Development 134(4): 747-755.

Kopan R, Ilagan MX (2009) The canonical Notch signaling pathway: unfolding the activation mechanism. Cell 137(2): 216-233.

Link MP, Goorin AM, Miser AW, Green AA, Pratt CB, Belasco JB, Pritchard J, Malpas JS, Baker AR, Kirkpatrick JA et al. (1986) The effect of adjuvant chemotherapy on relapse-free survival in patients with osteosarcoma of the extremity. New Engl J Med 314(25): 1600-1606.

Maier MM, Gessler M (2000) Comparative analysis of the human and mouse Heyl promoter: Hey genes are new Notch target genes. Biochem Biophys Res Commun 275(2): 652-660.

Mann CD, Bastianpillai C, Neal CP, Masood MM, Jones DJ, Teichert F, Singh R, Karpova E, Berry DP, Manson MM (2012) Notch3 and HEY-1 as prognostic biomarkers in pancreatic adenocarcinoma. PloS One 7(12): e51119.

Marina N, Gebhardt M, Teot L, Gorlick R (2004) Biology and therapeutic advances for pediatric osteosarcoma. Oncologist 9(4): 422-441.

Matsunoshita Y, Ijiri K, Ishidou Y, Nagano S, Yamamoto T, Nagao H, Komiya S, Setoguchi T (2011) Suppression of osteosarcoma cell invasion by chemotherapy is mediated by urokinase plasminogen activator activity via up-regulation of EGR1. PLoS One 6(1): e16234.

Nagao-Kitamoto H, Nagata M, Nagano S, Kitamoto S, Ishidou Y, Yamamoto T, Nakamura S, Tsuru A, Abematsu M, Fujimoto Y, Yokouchi M, Kitajima S, Yoshioka T, Maeda S, Yonezawa S, Komiya S, Setoguchi T (2014) GLI2 is a novel therapeutic target for metastasis of osteosarcoma. Int J Cancer 136(6): 1276-1284.

Nakagawa O, McFadden DG, Nakagawa M, Yanagisawa H, Hu T, Srivastava D, Olson EN (2000) Members of the HRT family of basic helixloop-helix proteins act as transcriptional repressors downstream of Notch signaling. Proc Natl Acad Sci USA 97(25): 13655-13660.

Purow B (2012) Notch inhibition as a promising new approach to cancer therapy. Adv Exp Med Biol 727: 305-319.

Sailer MH, Gerber A, Tostado C, Hutter G, Cordier D, Mariani L, Ritz MF (2013) Non-invasive neural stem cells become invasive in vitro by combined FGF2 and BMP4 signaling. J Cell Sci 126(Pt 16): 3533-3540.

Sakamoto M, Hirata H, Ohtsuka T, Bessho Y, Kageyama R (2003) The basic helix-loop-helix genes Hesr1/Hey1 and Hesr2/Hey2 regulate maintenance of neural precursor cells in the brain. J Biol Chem 278(45): 44808-44815.

Salie R, Kneissel M, Vukevic M, Zamurovic N, Kramer I, Evans G, Gerwin N, Mueller M, Kinzel B, Susa M (2010) Ubiquitous overexpression of Hey1 transcription factor leads to osteopenia and chondrocyte hypertrophy in bone. Bone 46(3): 680-694.

Searfoss GH, Jordan WH, Calligaro DO, Galbreath EJ, Schirtzinger LM, Berridge BR, Gao H, Higgins MA, May PC, Ryan TP (2003) Adipsin, a biomarker of gastrointestinal toxicity mediated by a functional gammasecretase inhibitor. J Biol Chem 278(46): 46107-46116.

Shao H, Huang Q, Liu ZJ (2012) Targeting Notch signaling for cancer therapeutic intervention. Adv Pharmacol 65: 191-234.

Sharff KA, Song WX, Luo X, Tang N, Luo J, Chen J, Bi Y, He BC, Huang J, Li X, Jiang W, Zhu GH, Su Y, He Y, Shen J, Wang Y, Chen L, Zuo GW, Liu B, Pan X, Reid RR, Luu HH, Haydon RC, He TC (2009) Heyl basic helix-loop-helix protein plays an important role in mediating BMP9induced osteogenic differentiation of mesenchymal progenitor cells. J Biol Chem 284(1): 649-659.

Sotobori T, Ueda T, Myoui A, Yoshioka K, Nakasaki M, Yoshikawa H, Itoh K (2006) Bone morphogenetic protein-2 promotes the haptotactic migration of murine osteoblastic and osteosarcoma cells by enhancing incorporation of integrin beta1 into lipid rafts. Exp Cell Res 312(19): 3927-3938.

Tanaka M, Setoguchi T, Hirotsu M, Gao H, Sasaki H, Matsunoshita Y, Komiya S (2009) Inhibition of Notch pathway prevents osteosarcoma growth by cell cycle regulation. Br J Cancer 100(12): 1957-1965.

Toole BP (2003) Emmprin (CD147), a cell surface regulator of matrix metalloproteinase production and function. Curr Top Dev Biol 54: 371-389.

van Es JH, van Gijn ME, Riccio O, van den Born M, Vooijs M, Begthel H, Cozijnsen M, Robine S, Winton DJ, Radtke F, Clevers H (2005) Notch/gamma-secretase inhibition turns proliferative cells in intestinal crypts and adenomas into goblet cells. Nature 435(7044): 959-963.

Villaronga MA, Lavery DN, Bevan CL, Llanos S, Belandia B (2010) HEY1 Leu94Met gene polymorphism dramatically modifies its biological functions. Oncogene 29(3): 411-420. 
Wang F, Xiao W, Sun J, Han D, Zhu Y (2014) MiRNA-181c inhibits EGFRsignaling-dependent MMP9 activation via suppressing Akt phosphorylation in glioblastoma. Tumour Biol 35(9): 8653-8658.

Wang Z, Banerjee S, Li Y, Rahman KM, Zhang Y, Sarkar FH (2006) Down-regulation of notch-1 inhibits invasion by inactivation of nuclear factor-kappaB, vascular endothelial growth factor, and matrix metalloproteinase-9 in pancreatic cancer cells. Cancer Res 66(5): 2778-2784.

Weiss KR, Cooper GM, Jadlowiec JA, McGough 3rd RL, Huard J (2006) VEGF and BMP expression in mouse osteosarcoma cells. Clin Orthop 450: $111-117$

Wu Y, Cain-Hom C, Choy L, Hagenbeek TJ, de Leon GP, Chen Y, Finkle D, Venook R, Wu X, Ridgway J, Schahin-Reed D, Dow GJ, Shelton A, Stawicki S, Watts RJ, Zhang J, Choy R, Howard P, Kadyk L, Yan M, Zha J, Callahan CA, Hymowitz SG, Siebel CW (2010) Therapeutic antibody targeting of individual Notch receptors. Nature 464(7291): 1052-1057.

Xin ZF, Kim YK, Jung ST (2009) Risedronate inhibits human osteosarcoma cell invasion. J Exp Clin Cancer Res 28: 105.
Zavadil J, Cermak L, Soto-Nieves N, Bottinger EP (2004) Integration of TGF-beta/Smad and Jagged1/Notch signalling in epithelial-to-mesenchymal transition. EMBO J 23(5): 1155-1165.

Zhang H, Wu H, Zheng J, Yu P, Xu L, Jiang P, Gao J, Wang H, Zhang Y (2013) Transforming growth factor betal signal is crucial for dedifferentiation of cancer cells to cancer stem cells in osteosarcoma. Stem Cells 31(3): 433-446.

Zhang W, Tu G, Lv C, Long J, Cong L, Han Y (2014) Matrix metalloproteinase-9 is up-regulated by CCL19/CCR7 interaction via PI3K/Akt pathway and is involved in CCL19-driven BMSCs migration. Biochem Biophys Res Commun 451(2): 222-228.

This work is published under the standard license to publish agreement. After 12 months the work will become freely available and the license terms will switch to a Creative Commons AttributionNonCommercial-Share Alike 4.0 Unported License.

Supplementary Information accompanies this paper on British Journal of Cancer website (http://www.nature.com/bjc) 